\title{
The Effect of Using Approximation and Appealing for Help Techniques on Learning Speaking Skill among Iranian Intermediate EFL Learners
}

\author{
Ehsan NamazianDoost \\ Department of English Language Teaching, Ahvaz Branch, Islamic Azad University, Ahvaz, Iran \\ Asadallah Hashemifardnya \\ Department of English Language Teaching, Ahvaz Branch, Islamic Azad University, Ahvaz, Iran \\ Nasrin Panahi \\ Department of English Language Teaching, Ahvaz Branch, Islamic Azad University, Ahvaz, Iran
}

\begin{abstract}
This study examined the effects of using approximation and appealing for the help techniques on learning speaking skill among Iranian intermediate EFL learners. First sixteen participants out of 120 were chosen for the target population. The participants were then randomly assigned to three equal groups- two experimental groups and one control group. The groups were pretested by a speaking pre-test. Regarding the treatment, the experimental groups were taught by using the communicative approach techniques including approximation and appealing for the help. One experimental group received instruction on how to appeal for the help if their competence cannot come up with the exact word. The other experimental group received instruction on how to compensate failure in conversation by using approximate words. For example, in case of forgetting the exact word they used an approximate word or phrase like using "boat" instead of "ship" or "pipe" for "water pipe". However, the participants in the control group received traditional activities in learning speaking such as question and answer, topic discussion, dialogs and role playing. The treatment took 10 sessions of 45 minutes each under the guidance of the supervisor. Then, the control group and the experimental groups took the post-test of pet. After collecting the data, they were analyzed through using Oneway Anova and Post-hoc Scheffe Test- Multiple Comparisons. The findings showed that both experimental groups outperformed than the control group. The results showed that those students who received appealing for the help treatment were better than approximation group and control group.
\end{abstract}

Index Terms - approximation, appealing for the help, speaking skill

\section{INTRODUCTION}

Approximation and appealing for the help are two techniques of communicative language teaching approach among the other techniques (e.g., Circumlocution-describing or exemplifying the target object or action, Word coinagecreating a non-existing L2 word based on a supposed rule, Class discussion-free or guided topics on various issues, etc.) in teaching EFL (Dörnyei, 1995). According to Akram and Mehmood (2011), approximation technique deals with utilizing an option term which communicates the significance of the objective lexical thing as nearly as could reasonably be expected (e.g., send for cruise pontoon) while engaging for enable alludes to swinging to the discussion to accomplice for help either straightforwardly (e.g., what do you call ...?) or by implication (e.g., rising inflection, delay, and eye to eye connection).

The aim of learning English is basically to improve communication ability for many learners. However, many EFL learners cannot communicate successfully in the target language maybe because they do not know how to use communicative approach strategies. Communication approach is a useful way to meet learners' communication needs. Different language teaching methods have been introduced in order to improve the quality of teaching and achieve the desired impact on students. Some of these methods could not develop the learners' ability to speak the target language fluently. This has given rise to new methods designed to overcome the limitations of the previous ones.

One of the most accepted trends in the field of foreign language teaching (FLT) is the communicative approach (CA), which was introduced in the 1970s by a group of European Council experts (e.g., Galloway, 1993). The fundamental rule that underlies the CA, as expressed by Nunan (1988) is that "students must learn not exclusively to make linguistically right, propositional explanations about the experiential world, yet should likewise build up the capacity to utilize dialect to complete things" (p. 25). Fundamentally, the CA "stresses the way that the understudies and their open intentions are at the very center of the showing program" (Finocchiaro \& Brumfit, 1983, p. 17). Although this approach 
tries to develop communicative skills of the students, Iranian students' communicative ability to speak English appropriately and effectively is still very poor. One reason, in my opinion, may be that Iranian high school English textbooks are not communicative-based; they are structurally based. Another reason could be attributed to EFL teachers' ignorance of the main principles of the CA. Bakarman (2004) found out that most EFL teachers have only a shallow knowledge of the theory and principles of the CA. Consequently, they could not help students to improve their ability to speak the target language effectively.

To sum up, a likely candidate for helping foreign language learners develop their ability to speak the target language fluently is the CA. It focuses on language use but at the same time attaches importance to language knowledge. Nattinger (1984) maintained that "new methods often go unmeasured and their claims remain unevaluated" (p. 404). This experimental study, therefore, examined two techniques of communicative approach to teach EFL learners oral proficiency. Canale (1983) characterized key ability as the dominance of verbal and non-verbal correspondence methods in L2 utilized when endeavoring to make up for insufficiencies in the linguistic and sociolinguistics skill or to improve the viability of correspondence. At the point when propelled students experience troubles in conveying importance in the objective dialect without finding any answer for adapt to their issues and when they believe they have no advance in learning it could lead them to end up noticeably on edge, demotivated and unsuccessful dialect students. Showing correspondence dialect procedures can be an answer for this issue and can enhance students' correspondence strategies, as well as abatement their uneasiness level, increment their inspiration and can make ready for students to wind up plainly more effective in EFL learning (Faerch \& Kasper, 1983).

\section{Statement of the Problem}

Foreign language teaching in Iran seems to have been long outdated. Traditional methods like Grammar Translation Method (GTM) continue to be used regardless of the more recent ones. Old methods used in teaching English in Iranian schools failed to motivate the students and instigate their involvement in class activities; this is why these methods are structurally based. The grammar oriented methods which are widely used in Iranian educational system are not producing desired results for a real communication. Accordingly, textbooks are structurally oriented and often not relevant to students' needs; too much emphasis is placed on the learning of grammar and vocabulary.

Although successful and fluent communication is the final goal of EFL learners, little effort is made to actually help them learn to speak English as it is spoken by native speakers. Therefore, Iranian learners have lots of problems to interact with their interlocutors in the target language. Many Iranian EFL learners are grammatically proficient and also they know abundant English vocabularies but they fail to communicate fluently. In addition, after studying English for some years, numerous EFL learners are not satisfied with their speaking proficiency level and become demotivated gradually. One of the reasons that English learners have difficulties in initiating and maintaining conversations may be due to the lack of teaching CSs used in classes for oral interactions. Teaching communicative-based techniques to EFL learners may be a useful way to develop their communicative competence and enhance their communication abilities. Therefore, teaching communicative-based techniques like approximation and appealing for the help may be a solution to this problem.

In addition, the books which are being used in Iranian schools concentrate on mechanical and formally meaningful drills, but do not allow for communicative ones. Moreover teacher-centered language instruction is the dominant form of ELT in Iran, where most teachers seem to prefer to focus on teaching grammar because, apparently, it does not require a high level of English proficiency on the part of the instructor. This assumption has been corroborated by AbuRas (2002), who found out that the traditional methods are compatible with the teachers' competence and training. He also found out that most teachers "do not feel linguistically, communicatively, and educationally competent" (p. 10). Consequently, they are likely to feel insecure about their English proficiency and would not be able to teach conversation to the students.

To rectify the current situation, a shift from structural approaches to the CA is critically needed. The latter has been accepted by many practitioners worldwide as a promising method for enhancing students' ability to communicate successfully in the target language. Thus the current study dealt with the effects of teaching communicative-based techniques-approximation and appealing for the help- to improve learners' speaking skills and also help them to become more successful and fluent in English conversations.

\section{OBJeCTIVES OF THE STUDY}

Communication strategies might be called without hesitation to make up for breakdowns in correspondence because of deficient capability. As it were, key capability alludes to the capacity to make them mean crosswise over effectively to open accomplices, particularly when issues emerge in the correspondence procedure. In this study, the significance and influence of two communication strategies were investigated.

The first purpose of this study was to examine the influence of communicative approach techniques including approximation and appealing for the help to develop Iranian EFL learners' speaking skill. The second objective of this research was to scrutinize if there is any difference between the EFL learners who received communicative approach techniques of either approximation or appealing for the help in improving their speaking skill. 


\section{RESEARCH QUESTIONS}

This study intended to address the following research questions:

RQ 1. Does communicative approach technique of approximation have any significant effect on Iranian EFL learners' speaking skill?

RQ 2. Does communicative approach technique of appealing for the help have any significant effect on Iranian EFL learners' speaking skill?

RQ 3. Is there any significant difference between the EFL learners who receive communicative approach techniques of approximation and appealing for the help in learning speaking skill?

\section{SignificANCE OF THE STUdy}

This study is significant since it provides some implications both for English teachers and learners to solve their communicative problems and helps them to improve their speaking skill. The findings of this study would enrich the ELT literature. It provides an insight into the effects of the CA on students' ability to understand English as used by native speakers of English. The recommendations of the study would help Iranian students to overcome or at least reduce the difficulties that they encounter when trying to communicate in English inside and outside the classroom. The findings of the study would help to influence the Ministry of Education to take into account the importance of implementing the $\mathrm{CA}$ and to provide teachers with pre- and in-service training in communicative teaching.

\section{REVIEW OF THE LITERATURE}

\section{A. Communication Strategy}

A communication strategy is characterized as a person's endeavor to figure out how to fill the hole between their correspondence exertion and quick accessible phonetic assets (Maleki, 2007). In spite of the fact that there are different meanings of correspondence systems also, the fundamental thought continues as before. For instance, Faerch and Kasper (1983) characterized CS as "possibly cognizant plans" which are utilized by a person to take care of an issue with a specific end goal to achieve a particular correspondence objective. It is trusted that correspondence procedures assume an essential part in the improvement of vital skill (e. g., Faucette, 2001); in this manner, one can characterize correspondence methodologies inside vital ability system. As per Canale and Swain (1980), vital capability is "verbal and non-verbal correspondence procedures that might be called without hesitation to adjust for breakdowns in correspondence because of execution factors or to inadequate fitness" (30). Scattergood (2003) trusted that vital fitness is developed if educators make a dialect classroom in which correspondence techniques are instructed and rehearsed.

The issue of correspondence methodologies has been and still is a vital theme in SLA. Van Lier (1988) believed that SLA happens through L2 students' dynamic support in discourse occasions. Rababah (2005) affirmed that raising awareness of CS is critical for various reasons; one being that it prompts learning by "evoking obscure dialect things from the conversationalist" (p. 194). He kept on saying that "... fruitful dialect learning is not just a matter of creating linguistic, sociolinguistic, and semantic capability, yet in addition the vital skill which includes the utilization of CSs ... " (p. 194). Additionally, Maleki (2007) trusted that utilization of correspondence methodologies is conductive to dialect learning and that "correspondence procedure preparing ought to be joined into school syllabuses ... " (p. 594). Different specialists, for example, Bialystok (1990), Dörnyei and Thurrel (1992), Dörnyei (1995), Oxford (2001), and numerous more have all commended the positive part of correspondence methodologies in instructing and taking in a moment dialect, particularly English.

\section{B. Taxonomy of Communication Strategies (CSs)}

Since the 1970s correspondence procedures have been the focal point of consideration in SLA look into. Around then investigation was centered around interlanguage and outside talk, both of which included the interactional idea of human correspondence (Tarone, 1977). These early investigations concentrated on distinguishing, characterizing and arranging CS into scientific categorizations. Later investigations, be that as it may, were focused on the connection between correspondence techniques and dialect training, particularly in EFL/ESL settings. When all is said in done there are two ways to deal with the investigation and arrangement of correspondence methodologies: the phonetic approach (interactional approach) and the subjective approach. Tarone (1977) was one who surprisingly recommended the phonetic approach, which was later extended by Faerch and Kasper (1983). As indicated by Tarone (1977), students' phonetic deficiency warrants CS use by conversationalists who attempt to pass on an importance being referred to each other. In this interactional approach, Tarone (1980) explained more on the meaning of CS by saying "... common endeavors of two questioners to concur on significance in circumstances where the imperative importance structures don't appear to be shared" (p. 419). As per her, "... importance structures incorporate both phonetic and socioetymological structure" (Tarone, 1980). Then again, psychological way to deal with CS is put inside psycholinguistic structure.

Faerch and Kasper (1983) clarified that correspondence procedures are forms happening inside the L2 speakers themselves with an attention on discourse recognition and arranging and execution in discourse creation at whatever point they experience issues (p. 212). Consequently, their portrayal of subjective approach is more student focused and 
informative techniques are seen as means for settling issues of self-articulation. Notwithstanding, as Mali (2007) put it "The CS execution process may begin off as psychological and result in connection" (p. 41). Also, Poulisse (1993) contended that one and a similar procedure sort can have components of both control and investigation (p. 171). The last is accentuated by Kellerman (1991) who considered correspondence procedures as appearances of the improvement of subjective procedures of examination and control. The etymological (interactional) and the psychological ways to deal with the examination of correspondence systems can be utilized to create typologies for the recognized CS. Tarone (1977, 1980) and Bialystock (1990) gave the most generally referred to scientific classification of correspondence systems, which are additionally talked about beneath. Tarone (1980, p. 429) outlined sorts of correspondence systems under five fundamental classes, alongside their subcategories. The rundown goes as takes after:

\section{A). Paraphrase}

Paraphrase includes three subcategories which are described below.

(a) Approximation: The use of a target language vocabulary item or structure, which the learner knows is not correct, but which shares semantic features with the desired item to satisfy the speaker (e. g., "pipe" for "water pipe").

(b) Word coinage: The learner's making up a new word in order to communicate a desired concept (e. g., "airball" for "balloon").

(c) Circumlocution: The learner's describing the characteristics or elements of an object or action instead of using the appropriate TL structure (e. g., "She is, uh, smoking something. I don't know what its name is. That's, uh, Persian, and we use in Turkey, a lot of").

\section{B). Transfer}

Transfer has two elements in it.

(a) Literal translation: The learner's translating word for word from the native language (e. g., "He invites him to drink" for "They toast one another").

(b) Language switch: The learner's using the NL (native language) term without bothering to translate (e. g., "balon" for "balloon" or "tirtil" for "turtle").

C). Appeal for Assistance

This refers to the learner's asking for the correct term or structure (e. g., "What is this?").

D). Mime

Mime refers to the learner's using non-verbal strategies in place of a meaning structure (e. g., clapping one's hands to illustrate applause).

\section{E). Avoidance}

Avoidance consists of two subcategories described below.

(a) Topic avoidance: The learner's by passing concepts for which the vocabulary or other meaning structures are not known to them.

(b) Message abandonment: The learner's beginning to talk about a concept but being unable to continue due to lack of meaning structure, and stopping in mid-utterance.

A series of other strategies called "achievement strategies" were proposed. They were named as so because it was believed that learners use their language resources to convey meaning, whether what they say is grammatically or socially correct. Mali (2007, p. 48) listed achievement production strategies as follows:

- Code-switching and gesticulation

- Literal translation and foreignizing

- Word coinage

- Simplification

- Generalization

- Paraphrase

- Restarts and approximation

- Establish foreign identity

- Appeal for repair and confirmation

\section{Speaking Skill}

For dominant part of individuals, the capacity of talking a remote dialect is synonymous with realizing that dialect since discourse is for them the essential instrument of human correspondence. English students never again expect the customary approach of their instructors in light of growing principally the syntactic fitness and utilizing system well known previously. Today, educators are relied upon to furnish their understudies with valuable dynamic information of the remote dialect, not only hypothesis about the dialect.

Open approach concentrates on a harmony amongst familiarity and precision and is the most reasonable for those understudies whose point is to pick up trust in talking and conversational capacities. In any case, talking in an outside dialect has regularly been seen as the most requesting of the four abilities. "While tuning in and perusing include the capacity to effectively get messages and are subsequently alluded to as open abilities, talking and composing, then again, include dialect generation and are alluded to as profitable aptitudes" (Harmer, 2000, p. 16).

Delivering talked dialect has regularly implied a trouble and a snag for English students. There might emerge an inquiry why. The appropriate response is self-evident. In the regular talked dialect understudies are required to know 
about attributes of familiar discourse, for example, diminished structures, utilization of slang or expressions, settled expressions, collocations and above all the pace of discourse. These must be mulled over while honing discussion in class. Without these, our talked dialect would sound academic and unnatural. To maintain a strategic distance from this, it is basic to present and practice "genuine" correspondence with our understudies inside the learning procedure. In the event that it is dismissed, it might be a motivation behind why understudies are regularly stunned and disillusioned when utilizing a remote dialect interestingly while cooperating in outside condition. They have not been set up for unconstrained correspondence and couldn't adapt to the greater part of its synchronous requests.

The embarrassment is usually caused by students' inability to adjust to native speakers' speech. This is natural and adjures patience while learning to speak or communicate in a foreign language. As I already mentioned, native speakers are a great support and the opportunity to communicate with them means even greater encouragement for our students. Although it is quite demanding for students to keep up in conversation with them, they take it as an advantage in their studies. Most English students are really acquainted with the way that the most ideal approach to propel their talking aptitudes is changing in accordance with it in an English talking condition.

\section{Methodology}

\section{A. Participants}

The participants of this study were 60 language learners who were selected among 120 intermediate students from Parsyan English language institute. English institute was located in Ahvaz, Iran. Participants' age range was from 12 to 20. They have been studying English as a foreign language for at least five years. Their level of English language proficiency was determined on the basis of their scores on the Oxford Placement Test (OPT). The learners were randomly divided into three groups including two experimental groups of Approximation, Appealing for the help and one control group. In each group both females and males were included.

\section{B. Instrumentation}

The first instrument of this study was the OPT (Appendix A). The validity of the test is self-evident. This test enabled the researcher to select those learners who were compatible with the conditions of the study. The OPT was used to assess students' language level. It also enabled the researcher to have a greater understanding of their level of proficiency (i.e., elementary, pre-intermediate, intermediate). According to the OPT, the learners whose scores were 39 and above (out of 70) were considered as the intermediate learners.

The speaking section of Preliminary English Test (PET) was selected for the pre-test and post-test of the study. The speaking section contained four parts. Each candidate interacted with the interlocutor. The interlocutor asked the candidates questions in turn, using standardized questions. The questions included giving information of a factual and personal kind. The candidates responded to questions about present circumstances, past experiences, and future plans. In the second task, candidates interacted with each other. Visual stimulus was given to the candidates to aid the discussion task. It should be mentioned that KR-21 formula was used to compute the reliability of pre-test and post-test. The results of computation revealed that the reliability of pre-test and post-test was 0.73 and 0.75 respectively. The validities of the pre and post-tests were confirmed by three English experts. It is worth nothing that before distributing the final version of the pre and post-tests among the target population, they were piloted on the similar group on the other English institute.

\section{Procedure}

First OPT was administered in order to manifest the participants' homogeneity in terms of English language proficiency. Sixteen participants out of 120 were chosen for the target population. The participants were then randomly assigned to three equal groups- two experimental groups and one control group. The groups were pretested by a speaking pre-test. Then, the participants of experimental groups received the same materials, speaking instruction, and the same amount of time was spent teaching speaking in each experimental class. Regarding the treatment, the experimental groups were taught by using the communicative approach techniques including approximation and appealing for the help. One experimental group received instruction on how to appeal for the help if their competence cannot come up with the exact word. For example, if students could not remember the correct target word like Smartphone, they were taught questions like "What do you call this in English?", "What does it mean in English?", "What's this/that?", "What are these/those?", "How do you say ... in English?", etc.". This technique can help speakers participate in the conversation and hold the floor and find correct answers for the questions they face.

The other experimental group received instruction on how to compensate failure in conversation by using approximate words. For example, in case of forgetting the exact word they used an approximate word or phrase like using "boat" instead of "ship" or "pipe" for "water pipe". Approximation strategy aids learners to find replacement for the vocabulary they either do not know or they have them in their passive reserve but are not able to remember them. This, in turn, will help students learn to hold their ground and do not stop the conversation.

However, the participants in the control group received traditional activities in learning speaking such as question and answer, topic discussion, dialogs and role playing. The treatment took 10 sessions of 45 minutes each under the guidance of the supervisor. Then control group and experimental groups took the post-test of PET. Their speaking 
activities (e.g., 2 or 3 minutes for each learner) on using the communicative approach techniques were recorded and scored by two raters through the speaking checklist (Hughes, 2003). Then the data were analyzed to get the results.

\section{Data Analysis}

When the collection of data through each method was finished, the data were processed and entered on the computer for data analysis. Finally, to analyze the collected data and measure the effects of communicative approach techniques on Iranian EFL learners' speaking skill, One- way ANOVA and Post-hoc Scheffe test were run to provide logical answers for the research questions.

\section{RESULTS}

In order to analyze the gathered data, the SPSS (Statistical Package for Social Science) software was used.

TABLE 1.

DESCRIPTIVE STATISTICS (THREE GROUPS)

\begin{tabular}{llllll}
\hline Groups & $\mathrm{N}$ & Minimum & Maximum & Mean & Std. Deviation \\
\hline Appeal-Pretest & 20 & 5.00 & 16.00 & 12.7500 & 3.00657 \\
\hline Appeal-Post-test & 20 & 10.00 & 20.00 & 17.0500 & 3.06894 \\
\hline Approx-Pre-test & 20 & 4.00 & 17.00 & 12.6500 & 4.36825 \\
\hline Approx-Post-test & 20 & 7.00 & 20.00 & 14.0500 & 4.14824 \\
\hline Control-Pre-test & 20 & 4.00 & 19.00 & 12.7000 & 3.68639 \\
\hline Control-Post-test & 20 & 7.00 & 19.00 & 13.2000 & 3.60701 \\
\hline Valid N (listwise) & 20 & & & & \\
\hline
\end{tabular}

Based on the descriptive statistics in the above table, all three groups' performance in the speaking pre-test was almost the same; their means show that they were at the same speaking proficiency level before applying the treatment. But regarding their speaking performance after the treatment, they did differently. The two experimental groupsappealing for the help and approximation- got better scores in their post-test. The mean scores of appealing for the help group and approximation group are 17.0500 and 14.0500 respectively in the posttest but the mean of control group is 13.2000 .

TABLE 2.

ONE-WAY ANOVA (PRE-TEST)

\begin{tabular}{llllll} 
& Sum of Squares & Df & Mean Square & F & Sig. \\
\hline Between Groups & .100 & 2 & .050 & .004 & .996 \\
\hline Within Groups & 792.500 & 57 & 13.904 & & \\
\hline Total & 792.600 & 59 & & & \\
\hline
\end{tabular}

Table 2 shows the scores of the three groups in the pre-test. Since the observed F (.004) is less than the critical F (3.15) with $\mathrm{df}=2 / 57$, the difference between the groups is not significant at $(\mathrm{p}<0.05)$. In fact, they performed the same in the pre-test.

TABLE 3

ONE-WAY ANOVA (POST-TEST)

\begin{tabular}{llllll} 
& Sum of Squares & Df & Mean Square & F & Sig. \\
\hline Between Groups & 163.633 & 2 & 81.817 & 6.192 & .004 \\
\hline Within Groups & 753.100 & 57 & 13.212 & & \\
\hline Total & 916.733 & 59 & & & \\
\hline
\end{tabular}

The above table indicates the post-test scores of both control and experimental groups. Since the observed F (6.191) is greater than the critical $F(3.15)$ with $d f=2 / 57$, the difference between the groups is significant at $(p<0.05)$. The experimental groups got better scores in the post-test of speaking. It can be claimed that the treatment affected the performance of the experimental groups in the post-test. As mentioned in the previous chapter, the researcher taught some techniques ("What does it mean in English?" and finding a replacement for the target vocabulary; "pipe" for "water pipe") to the experimental groups to compensate for their failure in conversation when they cannot remember the target word or when they do not know the exact English word. This table proves that the mentioned techniques bought success for the students of experimental group. 
TABLE 4.

POST-HOC SCHEFFE TEST, MULTIPLE COMPARISONS (POST-TEST)

\begin{tabular}{lllllll}
\hline & & & \multicolumn{3}{c}{$95 \%$ Confidence Interval } \\
(I) VAR00003 & $(\mathrm{J})$ VAR00003 & Mean Difference (I-J) & Std. Error & Sig. & Lower Bound Upper Bound \\
\hline Appeal-Post-test & Approx-Post-test & $3.00000^{*}$ & 1.14945 & .040 & .1109 & 5.8891 \\
\hline & Control-Post-test & $3.85000^{*}$ & 1.14945 & .006 & .9609 & 6.7391 \\
\hline Approx-Post-test & Appeal-Post-test & $-3.00000^{*}$ & 1.14945 & .040 & -5.8891 & -.1109 \\
\hline Control-Post-test & Control-Post-test & .85000 & 1.14945 & .762 & -2.0391 & 3.7391 \\
\hline & Appeal-Post-test & $-3.85000^{*}$ & 1.14945 & .006 & -6.7391 & -.9609 \\
\hline
\end{tabular}

*. The mean difference is significant at the 0.05 level.

Appealing group is significantly different with other groups but the Approximation group is not significantly different with the control group $(\mathrm{p}<0.05)$. The group which received instruction on appealing for the help to compensate their conversational failures got better scores in the post test in comparison to the other two groups.

Table 4 compares the scores of all groups in the post-test. Based on the above table, there is a significant difference between the post- test scores of appealing group and the post- test of approximation group $(p<0.05)$. There is a significant difference between the scores of the appealing group and the post- test of control group $(p<0.05)$. There is a significant difference between the post- test scores of approximation group and the post- test of appealing group $(\mathrm{p}<0.05)$. There is not a significant difference between the post-test of approximation group and the post- test of control group $(p<0.05)$. There is a significant difference between the post-test of control group and the post- test of appealing experimental group $(\mathrm{p}<0.05)$. There is not a significant difference between the post-test of control group and the posttest of approximation group $(\mathrm{p}<0.05)$.

\section{DISCUSSION}

To discuss the results of the research, the research questions are referred to as follows:

RQ 1. Does communicative approach technique of approximation have any significant effect on Iranian EFL learners' speaking skill?

Based on the results of the present study, the experimental group of approximation had more speaking proficiency than control group on the post-test. According to the data analysis, both experimental and control groups had almost the same scores in the pre-test but their scores in the post-test was different. Experimental group who received the instruction on using the communicative approach technique of approximation performed better in the post-test in comparison to the control group; they could speak English more fluently. The results proved that approximation helped the participants of experimental group to do better in the post-test.

The findings of the present study are in line with Maleki (2007) who investigated the teachability of CSs for university students. He used a textbook which dealt with specific CSs such as approximation, circumlocution, foreign zing, word coinage, appeals for assistance, and time stalling devices for the experimental group. The control group used a textbook without CS use. After four months, the experimental group performed better on the Cambridge ESOL speaking test and a house-made achievement test than the 66 'Free' to Choose: Communication Strategy Use in EFL Classrooms in ... control group. It was suggested that teaching CSs could be effective and conducive to English language learning.

This study also supports the findings of Saemian (1991); he investigated the relation between the effects of proficiency and the use of CSs among Iranian EFL learners. The researcher found statistically significant difference between the groups in terms of both frequency and types of CSs employed. The high proficiency group resorted to more circumlocution and approximation. Yet, the low proficiency group used more repetition, paralinguistic, avoidance, and code-switching.

RQ 2. Does communicative approach technique of appealing for help have any significant effect on Iranian EFL learners' speaking skill?

This study had two experimental groups; one of them received the instruction to compensate their speaking breakdowns through using "appealing for help". After analyzing the collected data it was proved that the mentioned group outperformed both the control group and the other experimental group. Appealing for help technique helped them to keep on their conversations despite of their English deficiencies.

The results of the study are compatible with the Majd's findings (2014), she investigated the effects of teaching communication strategies- Circumlocution, Approximation, Word coinage and Appeal for help- on anxiety level and motivation of Iranian students. In her study, a Cambridge Proficiency Test was used and 40 Iranian homogeneous participants among learners who were 12-14 years of age were selected. According to the results of the proficiency test, they were at intermediate level. The learners were taught how to use CSs during communication in the foreign language. At the end of 3-month teaching and applying these strategies to the class activities, oral and written Cambridge Proficiency Test were held again to determine whether there was an improvement in their communication skills. A five point Likert Scale questionnaire was also used to measure their anxiety level and motivation during communication in 
English after learning and using CSs. The findings of the study confirmed that teaching CSs to EFL learners and applying them to the class activities is a practical way to improve students communication skills, increase their motivation and decrease their anxiety level.

RQ 3. Is there any difference between the EFL learners who receive communicative approach techniques of approximation and appealing for help in learning speaking skill?

The participants of experimental groups received the same materials and speaking instruction, and also the same amount of time was spent teaching speaking in each experimental class. Regarding the treatment, the experimental groups were taught by using the communicative approach techniques including approximation and appeal for the help. One experimental group received instruction on how to appeal for help if their competence cannot come up with the exact word. The other experimental group received instruction on how to compensate failure in conversation by using approximate words. The results in chapter 4 shows that those students who used appealing for the help technique had better performance in the post-test of speaking in comparison of approximation group and also the control group. In fact, both strategies helped the students to improve their speaking skill. The results of this study support the findings which were discovered by Yarmohammadi and Seif (1992). They undertook research into the application of different CSs for solving students' oral and written communication problems. The researchers identified that strategies of literal translation, approximation and topic avoidance developed students' writing, while code switching, appealing for the help and approximation strategies improved oral tasks. The findings of the present study revealed that CSs can help Iranian EFL learners to lean speak English language more easily. So applying the CSs is suggested in Iranian English classes.

\section{CONCLUSION}

The present study tried to measure the effect of the communicative approach techniques of approximation and appealing for the help on speaking skills of some Iranian students. As mentioned in statement of the problem-Chapter One, different factors have made Iranian students unable to speak English fluently and appropriately. Among these factors is the dominance of traditional methods. A possible answer to this problem would be implementation of the communicative approach techniques of approximation and appealing for the help. After the implementation of communicative approach techniques of approximation and appealing for the help in the present study, the experimental groups outperformed the control group with a statistically significant difference. Overall, such results yielded an evidence of the positive effect of the communicative approach techniques on students' ability to understand and speak the target language effectively. Therefore, the present study recommends effective implementation of the communicative approach techniques with careful control of any constraints.

Generally it can be appeared from this information that correspondence system preparing was a compelling instrument for helping understudy's scaffold correspondence holes. By learning diverse procedures and an arrangement of center articulations, understudies turned out to be more sure about their capacity to convey, even in circumstances where they didn't completely see all the dialect, or when the individual they were speaking with did not comprehend them.

\section{REFERENCES}

[1] Akram, M., \& Mehmood, A. (2011). The need of communicative approach (in ELT) in teacher training program in Pakistan. Language in India, 11, 5, 172-178.

[2] Bakarman, H. O. (2004). Teachers' lack of awareness as a factor preventing the implementation of the communicative approach in female intermediate EFL classrooms. Unpublished master thesis, Umm Al-Qura University, Saudi Arabia.

[3] Bialystok, E. (1990). Communication strategies: A psychological analysis of second language use. Oxford, England: Blackwell.

[4] Canale, M. (1983). From communicative competence to communicative language pedagogy. In J. C. Richards \& R. W. Schmidt (Eds.), Language and communication. (pp. 2-27). London: Longman.

[5] Canale, M., \& Swain, M. (1980). Theoretical bases of communicative approaches to second language teaching and testing. Applied Linguistics, 1, 1-47.

[6] Dörnyei, Z. (1995). On the teachability of communication strategies. TESOL Quarterly, 29(1), 1-15.

[7] Dörnyei, Z., \& Thurrell, S. (1992). Conversation and dialogues in action. London: Prince Hall International

[8] Faerch, C., \& Kasper, G. (1983). Plans and strategies in foreign language communication. In Faerch, C., Kasper, G. (Eds.), Strategies in Interlanguage Communication. London: Longman.

[9] Faucette, P. (2001). A pedagogical perspective on communication strategies: Benefits of training and an analysis of English language teaching materials. Second Language Studies, 19, 2, 1-40.

[10] Finocchiaro, M., \& Brumfit, Ch. (1983). The Functional-notional approach: From theory to practice. Oxford: Oxford University Press.

[11] Galloway, A. (1993). Communicative language teaching: An introduction and sample activities. ERIC Clearinghouse on Languages and Linguistics Washington, DC. (ERIC Document Reproduction Service No. ED357642).

[12] Harmer, J. (2000). How to teach English. London: Longman.

[13] Kellerman, E. (1991). Compensatory strategies in second language research: A critiquea revision, and some (non-) implications for the classroom. In R Phillipson, E. Kellerman, L. Selinker, M. Sharwood Smith, \& M. Swain (Eds.). Foreign/ second language pedagogy research: A commemorative volume for Claus Faerch (pp. 142-161). Clevedon, UK: Multilingual Matters. 
[14] Majd, G. (2014). Teaching communication strategies to EFL learners and its impact on anxiety level and motivation: A hindering or facilitating factor? English for Specific Purposes World, Issue 42(15), 1-15

[15] Maleki, A. (2007). Teachability of communication strategies: An Iranian experience. System. 35(4), 583-594

[16] Nattinger, J. R. (1984). Communicative language teaching: A new metaphor. TESOL Quarterly, 18(3), 391-405.

[17] Nunan, D. (1988). Second Language Teaching and Learning. Boston: Heinle \& Heinle.

[18] Oxford, R. L. (2001). Language learning strategies. In Carter, R \& D. Nunan. Eds The Cambridge Guide to Teaching English to Speakers of Other Languages. UK: Cambridge University Press (pp. 166-72).

[19] Poulisse, N. (1990). The use of compensatory strategies by Dutch learners of English. Dordrecht, Holland: Foris.

[20] Rabab'ah, G. (2005). Communication problems facing Arab learners of English. Journal of Language and Learning 3 (1), 180197.

[21] Saemian, F. (1991). The relationship between proficiency level and the use of communicative strategies: A study of Persian EFL learners. (Unpublished Master's Thesis). Allameh Tabatabaee University, Tehran, Iran.

[22] Scattergood, E. (2003). Encouraging the use of strategies to improve communication in the EFL classroom. The Language Teacher Online. Retrieved, June, 2017, from http://jalt-publications.org/old_tlt/articles/2003/06/scattergood.

[23] Tarone, E. (1977). Conscious communication strategies in interlanguage: A progress report. In H. D. Brown, C.A. Yorio \& R. C. Crymes (Eds.) TESOL (pp194-203). Washington: TESOL.

[24] Tarone, E. (1980). Communication strategies, a foreigner talk and repair in interlanguage. Language Learning, 30, 417-431.

[25] Nunan, D. (1988). The learner-centered curriculum. Cambridge University Press: New York.

[26] Van Lier, L. (1988). The classroom and the language learner. London: Longman.

[27] Yarmohammadi, L., \& Seif, S. (1992). More on communicative strategies: Classification, resources, frequency and underlying processes. IRAL, 30(3), 223-232.

Ehsan NamazianDoost was born in Kohgiluyeh and Boyer-Ahmad Province of Iran in 1985. He holds an MA degree in TEFL from Islamic Azad University of Ahvaz. Now, he is a Ph.D. candidate in TEFL at Islamic Azad University of Shahr-e Kord. His main interest of research is second language acquisition, EFL teaching, teaching and testing, teaching speaking, communication and language learning strategies. His research papers and articles have been published by different international journals.

Asadallah Hashemifardnya was born in Khouzestan Province of Iran in 1987. He holds a master's degree in TEFL from Islamic Azad University of Ahvaz. He is a PhD student in TEFL at Islamic Azad University of Shahr-e Kord. His major research interests are teacher education, action research, mixed methods research, second language acquisition, and task-based language learning and teaching. He has published a number of articles in his areas of interest in academic journals.

Nasrin Panahi took his M.A degree in TEFL from Islamic Azad University of Ahvaz. She is currently a lecturer in English language teaching at different language institutes in Ahvaz. Her research interests involve psychological processes involved in learning English as a foreign language. 